in the cervix, urethra, or rectum. The patient may also admit further sexual intercourse.

5. The gonococcal complement fixation test may remain positive.

6. There is always the possibility of variation in the potency of the penicillin used.

Thus the results of treatment might be open to many various interpretations. Taken at the worst the results are not impressive, indicating a high failure rate.

The results of treatment in the small series of cases with proctitis are affected by the abovementioned variations. It can only be said that rectal testing is as vital in the tests of cure as in diagnosis, and that there is great scope for the improvement of such methods.

\section{Summary and Conclusions}

A study is made of various groups of patients attending the Whitechapel Clinic over a period of one year.

These cases are analysed under the main headings of (1) contact tracing, (2) diagnosis, and (3) treatment.
Special reference is made to the importance of gonococcal infection. of the ano-rectal region.

I should like to thank Mr. A. J. King, the Director of the Whitechapel Clinic, for his encouragement and help during the writing of this paper, and to acknowledge the co-operation of Dr. I. N. Orpwood Price and Dr. A. E. Wilkinson in the laboratory work involved.

\section{REFERENCES}

Ault, G. W. (1937). Amer. J. Syph., 21, 430.

Brunet, W. M., and Salberg, J. B. (1936). Ibid., $20,37$.

Clements, P. A., and Hughes, K. E. A. (1935). Lancet, $2,18$.

Hecker, A. F. (1801). "Deutliche Anweisung die venerischen Krankheitengenau zu erkennen und richtig zu behandeln, Erfurt." G. A. Keyser.

King, A. J., and Gallagher, E. (1946). Lancet, 1, 916.

and Mascall,.W. N. (1935). Ibid, 1, 1492.

McLeod, J. W. (1947).'Brit. J. vener. Dis., 2, 53.

Martin, C. L. (1935). J. Amer. med. Ass., 104, 192.

Price, I. N. O. (1933). " The Complement Fixation Test for Gonorrhoea." London County Council.

Ruys, A. C. (1934). Ned. Tijdschr. Geneesk., 78, 5533. (1939). Indian J. vener. Dis., 5, 81.

Thomson, D. (1923). "Gonorrhœa." London. Henry Froude and Hodder and Stoughton.

Yeomans, F. C. (1929). "Proctology." New York and London. D. Appleton Co.

\title{
DISCUSSION ON GONORRHEA IN THE FEMALE
}

DR. G. L. M. McElligótr said he was delighted to hear of Dr. Nicol's success with the contact slip method of contact tracing, which he probably saw for the first time at St. Mary's Hospital and from which very good results were still obtained. One of the reasons why the results of the treatment of gonococcal proctitis with penicillin in Dr. Nicol's cases were so depressing might be the fact that a very large amount of penicillinase was produced in the rectum by the $B$. Coli and it was almost an indication for concurrent sulphonamide treatment in such cases.

Dr. Robert LeES said that Dr. Nicol's case follow-up and contact-tracing aroused his admiration. It was very difficult indeed, even with the help of an experienced social worker, to get contact-tracing such as had been reported.

He had occasion recently to question a small boy of 12 who had contracted acute gonorrhoa. This led to proof that his consort was a small girl of 9 years. The girl's mother was an old patient of the clinic; she was probably a prostitute, and she had also a lodger, a man who was suffering from both gonorrhœea and syphilis. The story was that the lodger had interfered with the small girl and she had subsequently seduced the small boy.

He was interested to find out who questioned the patients, as female patients were often reluctant to talk to a man about their sexual affairs ; many of them would admit to one sexual exposure or one sexual partner, but it was exceedingly difficult to get them to admit to the promiscuity to which one was accustomed in the male, although one was often satisfied that they were completely " farmyard " in their behaviour.

Regulation 33B was not mentioned, and it coincided with his experience that this regulation was not effective in tracing contacts.

A positive contribution of the paper was the emphasis on the high incidence of anal and rectal infections, and the fact that these could be present but unsuspected and could only be found after extensive examinations. He had not found the same percentage that was described, probably because he had not looked for it. Anal infection was common in vulvovaginitis in young girls. For ano-rectal infections he had always used local treatment in addition to specific treatment, using irrigations with potassium permanganate and a suppository containing a flavine compound. These were well tolerated and results of treatment were satisfactory.

Mr. A. J. KING was sorry to hear that Dr. Lees did not use the method of vaginal plate culture. It was ten years since that method was recommended by Dr. Mascall and himself, and the test had received less attention than 
its value warranted. By its use it was possible to make the diagnosis of gonorrhoea in a number of cases in which all other tests were negative. It was true that in Dr. Nicol's series the test did not show up well, but this was in a period when the culture medium was not at its best. He believed no test should be neglected for a condition so difficult to diagnose as gonorrhœa in the female.

Dr. Nicol mentioned that he treated one of his patients with penicillin in a mixture of beeswax and ethyl-oleate. He would be interested to hear the experience of others with this particular preparation which had been marketed as one which delayed the absorption of penicillin from the site of injection, and was used in many clinics as a substitute for preparations employing beeswax and arachis oil. Dr. Wilkinson had been able to estimate blood levels of penicillin in a few cases after injections of this preparation. His test organism, the Oxford staphylococcus; admittedly was not the most sensitive available. His results seemed to show that the preparation was no more effective than watery solution in maintaining a blood level of penicillin which was therapeutically effective. He would like to know if any other members present had had similar experience, because if the ethyl-oleate-wax mixture was not a delayer of absorption, many people were using it under an entire misapprehension.

DR. A. H. HARKNESS did not agree with Dr. Nicol that ano-rectal gonorrhœa in the male was a rare disease, as he had treated large numbers of such cases both at hospital and in his private practice.

During the last ten years he had studied the pathology of gonorrhœa from biopsy material of rectal mucosa, anal mucosa and skin of anal canal, and he considered the portal of entry of the gonococcus in this type of infection to be the columnar secreting epithelium of the rectum. Gonococci were found in patchy disorganized areas of this epithelium and in the sub-epithelial connective tissue of rectum and anal canal. He had not seen gonococci in the epithelium of mucosa of the anal canal or in the skin of the anal canal.

He agreed with Dr. Nicol that the signs and symptoms are often slight, but he had seen cases in which they were severe. Proctoscopy in the acute cases revealed a generalized redness of the rectal mucosa, with large red and soft infiltrations which bled easily and bulged into the end of the speculum. Few changes were observed in the anal canal, whereas in the subacute or chronic disease more lesions were seen there than in the rectum. Patchy areas of redness or more conspicuous soft infiltrations, red or pale in colour, were seen chiefly in the anal canal, being especially well marked at the ano-rectal junction and on and between the columns of Morgagni. In the acute stage a frankly purulent discharge (occasionally hæmorrhagic) was seen in the rectum, whereas in the subacute stage the pus was usually streaky or in small clumps with excess of mucus in both rectum and anal canal.

Fistulæ and small ulcers in the skin of the anal canal and the skin of the anus might occur during the course of the disease, but condylomata acuminata, situated on the skin of the anus or in the anal canal (up to and including the ano-rectal junction), were the most frequent lesions seen in association with the disease : there might also be blood-borne complications such as arthritis.

A diagnosis of ano-rectal gonorrhœa could often be made by everting the lips of the anus two or three times and examining the secretion which appeared at the anal orifice. The members knew his views concerning the gonococcal complement fixation test, and he felt that the large percentage of positive reactions reported by
Dr. Nicol showed that the majority of his cases were suffering from infections which were secondary to uro-genital disease.

Dr. Harkness recently treated two cases of Waelsch urethritis contracted by sodomy, and urethral washings in both yielded pure cultures of pleuropneumonialike organisms. Anal swabs from the only contact examined were also positive for pleuropneumonia-like organisms.

Dr. Jean Morton thanked Dr. Nicol for drawing attention to the fact that the female rectum was so often infected. Before 1935 she did not examine rectums, but after visiting Germany and watching the painstaking examinations performed there, she did so and found that 13 per cent. of women with gonorrhœa had infected rectums. In those days the out patients were given sulphapyridine or prontosil, and they could not tolerate the large doses one could give to in patients. The infected rectums were treated locally with $10 \mathrm{c.cm}$. of 20 per cent. aqueous solution of mercurochrome, which was retained as long as possible. This treatment gave good results. In the war she was not so assiduous because the patients were given much larger doses, but she found now that patients treated with penicillin were not responding well and she was going to treat the rectal infection with some local preparation. She agreed that very few patients complained of symptoms. One patient had an anal fistula and another had an ischio-rectal abscess. This area was a source of infection, and very frequently might be a cause of the recurrence. All patients suspected of gonorrhœa, and during the follow-up period after treatment of a proved gonorrhœa, should undergo a rectal examination.

DR. NICOL, in reply, admitted that in his series of cases results had been assessed after using penicillin alone. He agreed that it was possible that some form of local treatment, or the combination of penicillin with sulphathiazole, might produce better results. At the Whitechapel Clinic at the present moment first-class culture results were being obtained, and he hoped these would continue.

At Whitechapel the medical officer saw the patient first, and took her history; after this she was interviewed by the social service worker. One great advantage of a social service worker was that she often obtained information which the medical officer had not obtained. The best results were obtained by co-operation between the medical officer and the social service worker.

The disadvantage of not using smears for diagnosis was the time lost. Patients who were diagnosed only by culture methods often defaulted before treatment because the diagnosis was made after they had left the clinic and a proportion of patients never returned. This was an important point, and he would advocate that smears be taken however high the standard of culture results might be. As far as the vaginal plate technique was concerned, as Mr. King had mentioned, a certain number of diagnoses were obtained by this method alone and if it gave the diagnosis even in one or two cases in a hundred he would consider it justified.

Dr. Nicol said that a contact was not necessarily infected. It was known from the recent work of Mahoney in U.S.A. that gonococci could be introduced into the male urethra and the patient still remain uninfected: It could only be said of this series that either the diagnosis of gonorrhwa had not been made or the contacts were not infected.

The question of the dosage of penicillin raised several 
difficult problems. Extreme care must be taken not to raise the dosage because of the risk of suppressing possible concomitant syphilitic infection. Many workers preferred to use sulphathiazole alone, or a combination of sulphathiazole with a lower dosage of penicillin, because of this risk. In the few cases in which a higher dosage of penicillin had been used, because the patients were also infected with syphilis, results were inconclusive and treatment failure did occur.

The low incidence of male rectal infection Dr. Nicol had mentioned in this paper was based on figures quoted in the literature. He did not pretend to have experience comparable to that of Dr. Harkness, and it might well be that rectal infection in the male was more common. He was interested to hear that St. Mark's Hospital was using a modified Graeme Anderson proctoscope of a smaller size. He had also tried a smaller proctoscope with internal illumination, and a satisfactory view of the rectal wall was not obtained. He noted Dr. Morton's experience in Germany with interest. In that country rectal testing had been used extensively. The last speaker had asked why he had obtained such a small percentage of positive rectal cultures. The main difficulty was that the plate or slope was so often overgrown by colonies of $B$. Coli. Clements and Hughes in their paper stated they had used various selective media without success. It was best to use a medium on which gonococci grew well using the oxidase test, so that any oxidase positive colonies could be picked off the plate from among the colonies of other organisms.

\section{BOOK REVIEWS}

\section{AN INTRODUCTION TO DERMATOLOGY}

By G. H. Percival

(Eleventh edition. Edinburgh: $E$. and $S$. Livingstone. 1947. Pp. 349. 233 illustrations, the majority in colour. Price 35s. net.)

The eleventh edition of this book, which was previously edited by Dr. Percival in conjunction with its originator, Sir Norman Walker, is in reality a new work. Many developments have occurred in dermatology since the first edition of the work appeared in 1899. The opportunity has been taken in the present edition of rewriting the script to incorporate the many developments which have been gradually added to the previous editions. In doing so Dr. Percival has succeeded in maintaining the original traditions and methods, but at the same time he has produced the most compact and valuable contribution to the speciality of dermatology. Special notice should be taken of the very extensive consideration of the histological changes associated with the common skin diseases; these are magnificently illustrated with coloured plates and they are a feature of the book which at once singles it out in comparison with the other works on the subject.

The methods of treatment are clearly discussed, and details of the technique employed for the suitable treatment of lesions is outlined in full. It is impossible to include anything beyond the more common diseases in a work of this size, which only claims to be an introduction to the subject, and as such it attains a very high standard and should be a most popular addition to the library of dermatological works. Both the author and the publisher deserve credit for the standard which has been achieved.

\section{COMMON SKIN DISEASES}

By A. C. Roxburgh

(Eighth edition. London : H. K. Lewis. 1947. Pp.497; 212 illustrations, 8 plates in colour. Price 21s.)

The recent advances in dermatology have been included in this eighth edition of Roxburgh's popular handbook on skin diseases. The extent of its popularity is evidenced by the appearance of a new edition at so early a date.

This edition maintains the characteristics of. previous ones, and is well produced with clear printing and good paper. Several new illustrations have been added, and the text has been very considerably revised. Penicillin is considered in greater detail as a result of the wider experience in the uses of this compound since the appearances of the last edition. The treatment of lupus vulgaris with calciferol is included, and reference is made to the dangers of local sulphonamide treatment. The text has been enlarged by reference to less common conditions, such as adenoma sebaceum, erysipeloid, acrodermatitis perstans, ticks, and jelly-fish stings. The work is clearly written and presents a very fair picture of the more common skin diseases ; consideration of treatment has been very considerably increased, but it is unfortunate that no clear indication is given of the form of treatment which might be especially applicable to any particular type of skin disease.

The work remains one of the most popular short books on dermatology, and it will serve both the student and practitioner as a useful introduction to the subject.

D.E. 